\title{
Berberine, a natural cholesterol reducing product, exerts antitumor cytostatic/cytotoxic effects independently from the mevalonate pathway
}

\author{
TADEUSZ ISSAT, MAREK JAKÓBISIAK and JAKUB GOLAB \\ Department of Immunology, Center of Biostructure Research, The Medical University of Warsaw, Warsaw, Poland
}

Received June 13, 2006; Accepted September 7, 2006

\begin{abstract}
The aim of this study was to investigate the role of the mevalonate pathway in the cytostatic/cytotoxic effects of berberine, a natural plant alkaloid that reduces cholesterol concentration. Berberine as well as lovastatin, an inhibitor of the mevalonate pathway, exerted dose-dependent cytostatic/ cytotoxic effects against human breast cancer cells (MDAMB231). Although the mevalonate pathway metabolites (mevalonic acid, farnesyl pyrophosphate, geranylgeranyl pyrophosphate) effectively reversed cytostatic/cytotoxic effects of lovastatin against MDA-MB231 cells, they were not effective in influencing the cytostatic/cytotoxic effects of berberine. The cytostatic/cytotoxic effects of berberine do not seem to result from inhibition of the mevalonate pathway.
\end{abstract}

\section{Introduction}

Berberine, a naturally occurring isoquinoline alkaloid, produced by a number of important medicinal plants, such as Berberis vulgaris (barberry), Berberis aristata (tree turmeric), Berberis aquifolium (Oregon grape) or Tinospora cordifolia, has been shown to exert potent anti-inflammatory and antitumor properties in in vitro as well as in vivo systems (1-4). Berberine has also been shown to significantly decrease cholesterol levels in mice (5). The mechanism of this latter effect has not been elucidated and remains poorly understood. Similarly, the mechanisms of its antitumor effects are poorly defined. Berberine was demonstrated to inhibit activator

Correspondence to: Dr Jakub Golab, Department of Immunology, Center of Biostructure Research, The Medical University of Warsaw, Chalubinskiego 5, 02-004 Warsaw, Poland

E-mail: jgolab@ib.amwaw.edu.pl

Abbreviations: AP-1, activator protein 1; Cdk, cyclin dependent kinase; COX-2, cyclooxygenase 2; FBS, fetal bovine serum; FPP, farnesyl pyrophosphate; GGPP, geranylgeranyl pyrophosphate; HMG-CoA, 3-hydroxy-3-methylglutaryl-coenzyme A; MA, mevalonic acid; MMP, matrix metalloproteinase

Key words: berberine, cholesterol, mevalonate pathway protein 1 (AP-1) and cyclooxygenase 2 (COX-2) transcriptional activities $(6,7)$. Its inhibitory effects on invasion of lung cancer cells correlate with decreased production of urokinase-plasminogen activator and matrix metalloproteinase-2 (MMP-2) (8). Berberine-induced antiproliferative effects against prostate carcinoma cells was associated with G1-phase arrest that correlated with inhibition of expression of cyclins D1, D2 and E; cyclin dependent kinases (Cdk) 2, Cdk4 and Cdk6; and increased expression of Cdk inhibitory proteins p21 Cip1 and p27 ${ }^{\text {Kip } 1}$ (9). Intriguingly, similar cytostatic effects are frequently ascribed to statins which are potent inhibitors of 3-hydroxy-3-methylglutaryl-coenzyme A (HMG-CoA) reductase, the major rate-limiting enzyme that controls the conversion of HMG-CoA to mevalonic acid (MA) (10). MA is the precursor in the biosynthesis of isoprenoid compounds including cholesterol, dolichol and ubiquinone. Furthermore, mevalonate-derived prenyl groups enable precise cellular localization and function of many proteins such as Ras and Rho proteins. Statins have been shown to inhibit proliferation and to induce apoptosis in a variety of tumor cells. They have also been found to display antitumor effects against melanoma, mammary carcinoma, pancreatic adenocarcinoma, fibrosarcoma, glioma, neuroblastoma, and lymphoma in animal tumor models resulting in retardation of tumor growth, and/or inhibition of the metastatic process (11-14).

Since both statins and berberine are effective cholesterolreducing agents and seem to exert similar mechanisms of cytostatic/cytotoxic activity against tumor cells we decided to verify whether berberine can exert cytostatic/cytotoxic effects by inhibiting the mevalonate pathway which was previously demonstrated to be the major mechanism of antitumor action of statins.

\section{Materials and methods}

Tumor cells. Breast cancer MDA-MB-231 cells from ATCC (American Type Culture Collection, Rockville, MD, USA) were used throughout all experiments. Cells were maintained in RPMI-1640 medium (Invitrogen Co., Paisley, UK), supplemented with $10 \%$ heat-inactivated fetal bovine serum (FBS), antibiotics, 2-mercaptoethanol $(50 \mu \mathrm{M})$ and L-glutamine ( $2 \mathrm{mM}$ ) (all from Invitrogen Co.), hereafter referred to as culture medium. Cells were cultured in $75 \mathrm{~cm}^{2}$ tissue flask (Corning, NY, USA) at $37^{\circ} \mathrm{C}$ in a fully humidified atmosphere of $5 \% \mathrm{CO}_{2}$, and were routinely passaged every 3-4 days after 


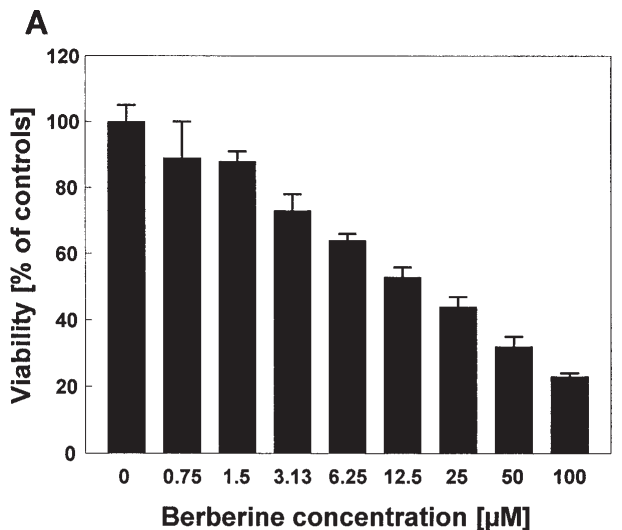

B

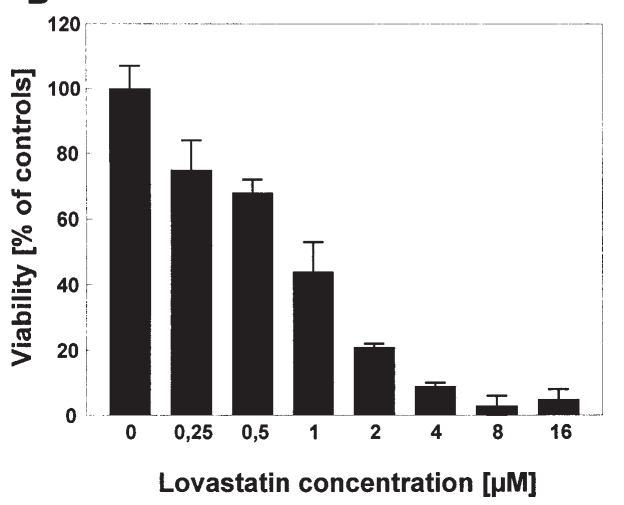

Figure 1. Cytostatic/cytotoxic effects of berberine and lovastatin against MDA-MB231 cells. Tumor cells were incubated with serial dilutions of berberine (A) or lovastatin (B) for $48 \mathrm{~h}$. The cytostatic and/or cytotoxic effects of treatment were measured with a standard crystal violet staining assay.

short trypsinization with trypsin/EDTA (Invitrogen Co.) $(15,16)$.

Reagents. Lovastatin (Merck, Sharp \& Dohme Res. Lab., Rahway, NJ, USA) was obtained in the inactive lactone form that was converted to the active form as described (17). Berberine chloride, farnesyl pyrophosphate (FPP) and geranylgeranyl pyrophosphate (GGPP) were purchased from Sigma Chemical Co. (St. Louis, MO, USA).

Cytostatic/cytotoxic assay. The cytostatic and/or cytotoxic effects of treatment of tumor cells were measured using crystal violet staining as described (18). Briefly, tumor cells were dispensed into 96-well plates (Nunc) at a concentration of $5 \times 10^{3}$ cells per well/100 $\mu$ l. The following day all reagents were added. Then, $48 \mathrm{~h}$ after incubation with reagents the cells were rinsed with PBS and stained with $0.5 \%$ crystal violet in $30 \%$ ethanol for $10 \mathrm{~min}$ at room temperature. Plates were washed 4 times with tap water and the cells were lysed with $1 \%$ SDS solution. Absorbance was measured at $595 \mathrm{~nm}$ using an enzyme-linked immunosorbent assay reader (SLT Labinstrument GmbH, Salzburg, Austria), equipped with a $595 \mathrm{~nm}$ filter. Cytotoxicity was expressed as relative viability of tumor cells (\% of control cultures incubated with medium only $)$ and was calculated as follows: relative viability $=\left(\mathrm{A}_{\mathrm{e}}\right.$ - $\left.A_{b}\right) \times 100 /\left(A_{c}-A_{b}\right)$, where $A_{b}$ is the background absorbance, $A_{e}$ is experimental absorbance, and $A_{c}$ is the absorbance of untreated controls.

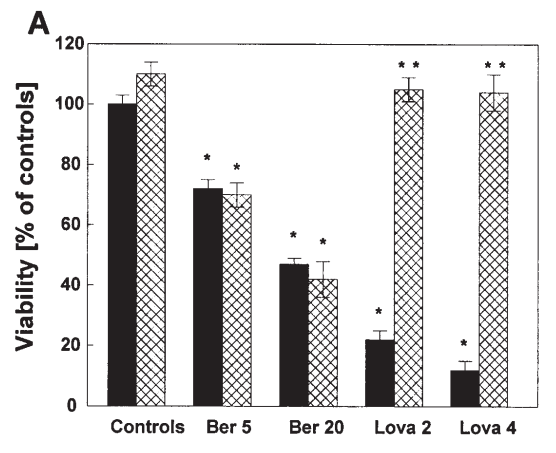

MA concentration
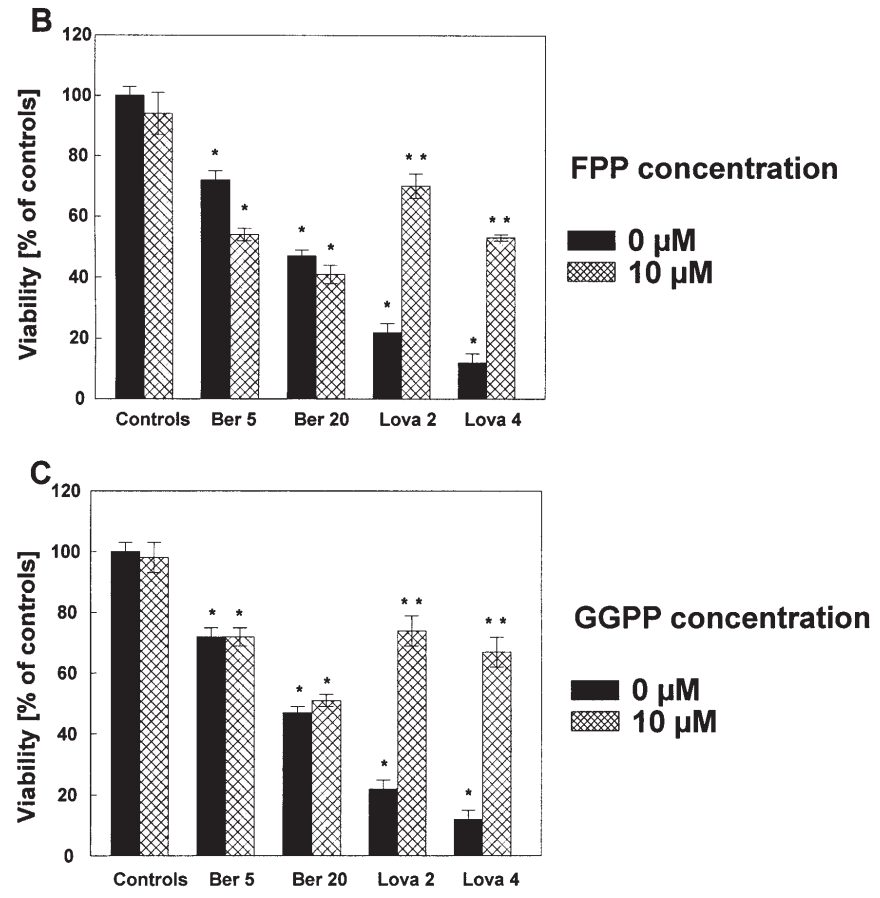

Figure 2. The influence of the mevalonate pathway on the cytostatic/ cytotoxic effects of berberine and lovastatin. Tumor cells were incubated with berberine at 25 or $50 \mu \mathrm{M}$ concentration or with lovastatin at 2 and $4 \mu \mathrm{M}$ concentrations for $48 \mathrm{~h}$. Mevalonic acid (MA) was used at a concentration of $200 \mu \mathrm{M}$, farnesyl pyrophosphate (FPP) and geranylgeranyl pyrophosphate (GGPP) were used at $10 \mu \mathrm{M}$ concentration. The cytostatic and/or cytotoxic effects of treatment were measured with a standard crystal violet staining assay. ${ }^{*} \mathrm{P}<0.05$ as compared with controls; ${ }^{* *} \mathrm{P}<0.05$ as compared with lovastatin-treated cells.

Statistical analysis. Data were calculated using Microsoft ${ }^{\mathrm{TM}}$ Excel 98. Differences in in vitro cytotoxicity assays were analyzed for significance by Student's t-test. Significance was defined as a two-sided $\mathrm{p}<0.05$.

\section{Results}

In the initial experiments we determined the concentrations of lovastatin and berberine required for the inhibition of MDA-MB231 cell proliferation in a standard crystal violet staining assay. These experiments revealed that MDA-MB231 cells are more resistant to cytostatic/cytotoxic effects of berberine for which the $\mathrm{IC}_{50}$ was $25 \mu \mathrm{M}$ at an incubation time of $48 \mathrm{~h}$ (Fig. 1A). $\mathrm{IC}_{50}$ for lovastatin was $1.0 \mu \mathrm{M}$ (Fig. 1B).

To investigate the role of the mevalonate pathway in the cytostatic/cytotoxic effects of berberine and lovastatin, the cultures of MDA-MB231 cells were supplemented with 
either mevalonic acid (at $200 \mu \mathrm{M}$ concentration), farnesyl pyrophosphate or geranylgeranyl pyrophosphate (both used at $10 \mu \mathrm{M}$ concentration). Again, a dose-dependent inhibition of tumor cell proliferation was observed. Lovastatin-mediated cytostatic/cytotoxic effects were almost completely reversed by all three mevalonate pathway metabolites. For example, lovastatin at $2 \mu \mathrm{M}$ concentration decreased viability of MDAMB231 cells to $22 \pm 3 \%$ as compared to controls, MA reversed the lovastatin-induced effect to $105 \pm 4 \%$, FPP to $70 \pm 4 \%$, and GGPP to $74 \pm 5 \%$ (Fig. 2A-C). At identical experimental conditions berberine-elicited effects were not revered by neither MA, FPP nor GGPP (Fig. 2A-C).

\section{Discussion}

Cholesterol-reducing agents are commonly used to prevent and to treat coronary heart disease and are among the most widely prescribed drugs in Western countries. Six statins (atorvastatin, fluvastatin, lovastatin, pravastatin, rosuvastatin and simvastatin) are currently available for clinical use. Their interference with many critical biologic processes makes their effects extremely pleiotropic and among their potential effects there is an antitumor activity. Cholesterol-reducing drugs are most commonly used in elderly patients who, because of their age, have an increased incidence of cancer. Therefore, their potential antitumor effects are particularly interesting. Statins have been found to induce cytostatic and cytotoxic effects against tumor cells in vitro (19-23) and to exert antitumor effects in experimental tumor models $(24,25)$. Several studies revealed that long-term use of statins is associated with diminished cancer incidence $(26,27)$.

Increasing evidence indicates that berberine, an ancient herbal medicine that decreases cholesterol concentration in humans, exerts potential anticancerogenic and antitumor effects. Berberine was shown to exert direct antiproliferative and pro-apoptotic effects towards tumor cells. Moreover, it can inhibit invasiveness of tumor cells, tumor-associated angiogenesis and shows promising anticachectic effects (28). Despite numerous potential mechanisms it has still not been elucidated as to how berberine might influence the growth of tumor cells. The aim of this study was to verify whether berberine might exert its cytostatic/cytotoxic effects through the inhibition of the mevalonate pathway. The mevalonate pathway is the source of cellular cholesterol as well as a number of lipid metabolites used for post-translational modification of cellular proteins. Mevalonate-derived prenyl groups are attached to $\sim 1 \%$ of cellular proteins and are required for their correct cellular localization and function. These proteins are either farnesylated or geranylgeranylated and include lamins, Ras and Rho proteins. Interference with the processing of Ras and Rho proteins might explain the observed cytostatic/cytotoxic effects of berberine against numerous tumor cells in vitro. Metabolites of the mevalonate pathway (MA, FPP and GGPP) effectively reversed cytostatic/ cytotoxic effects of lovastatin thereby confirming the mevalonate pathway-dependent anti-tumor effects of statins. However, neither MA, FPP nor GGPP influenced cytostatic/ cytotoxic effects of berberine.

Altogether our studies indicate that the cytostatic/cytotoxic effects of berberine do not result from inhibition of the mevalonate pathway. Further studies are required to elucidate the mechanisms that lead to antiproliferative and pro-apoptotic effects of berberine.

\section{Acknowledgements}

The study was supported by grants 01/1M19/NM8, 1M19/N and 1M19/W1 from the Medical University of Warsaw.

\section{References}

1. Kuo CL, Chi CW and Liu TY: The anti-inflammatory potential of berberine in vitro and in vivo. Cancer Lett 203: 127-137, 2004

2. Lin CC, Kao ST, Chen GW, Ho HC and Chung JG: Apoptosis of human leukemia HL-60 cells and murine leukemia WEHI-3 cells induced by berberine through the activation of caspase- 3 . Anticancer Res 26: 227-242, 2006.

3. Lin JP, Yang JS, Lee JH, Hsieh WT and Chung JG: Berberine induces cell cycle arrest and apoptosis in human gastric carcinoma SNU-5 cell line. World J Gastroenterol 12: 21-28, 2006.

4. Kang MR and Chung IK: Down-regulation of DNA topoisomerase IIalpha in human colorectal carcinoma cells resistant to a protoberberine alkaloid, berberrubine. Mol Pharmacol 61: 879-884, 2002.

5. Kong W, Wei J, Abidi P, Lin M, Inaba S, Li C, Wang Y, Wang Z, Si S, Pan H, Wang S, Wu J, Wang Y, Li Z, Liu J and Jiang JD: Berberine is a novel cholesterol-lowering drug working through a unique mechanism distinct from statins. Nat Med 10: 1344-1351, 2004.

6. Fukuda K, Hibiya Y, Mutoh M, Koshiji M, Akao S and Fujiwara H: Inhibition by berberine of cyclooxygenase-2 transcriptional activity in human colon cancer cells. J Ethnopharmacol 66: 227-233, 1999.

7. Fukuda K, Hibiya Y, Mutoh M, Koshiji M, Akao S and Fujiwara $\mathrm{H}$ : Inhibition of activator protein 1 activity by berberine in human hepatoma cells. Planta Med 65: 381-383, 1999.

8. Peng PL, Hsieh YS, Wang CJ, Hsu JL and Chou FP: Inhibitory effect of berberine on the invasion of human lung cancer cells via decreased productions of urokinase-plasminogen activator and matrix metalloproteinase-2. Toxicol Appl Pharmacol 214: 8-15, 2006.

9. Mantena SK, Sharma SD and Katiyar SK: Berberine, a natural product, induces G1-phase cell cycle arrest and caspase-3dependent apoptosis in human prostate carcinoma cells. Mol Cancer Ther 5: 296-308, 2006.

10. Jakobisiak M and Golab J: Potential antitumor effects of statins (Review). Int J Oncol 23: 1055-1069, 2003.

11. Issat $\mathrm{T}$, Nowis D, Jakobisiak M and Golab J: Lovastatin potentiates antitumor effects of saquinavir against human lymphoma cells. Oncol Rep 12: 1371-1375, 2004.

12. Kaminski R, Kozar K, Kopec M, Basak G, Skierski JS, Koronkiewicz M, Jakobisiak M and Golab J: Discussion on 3-hydroxy-3-methylglutaryl-coenzyme a reductase inhibitors reduce human pancreatic cancer cell invasion and metastasis. Gastroenterology 123: 1747-1748, 2002

13. Fritz G: HMG-CoA reductase inhibitors (statins) as anticancer drugs (Review). Int J Oncol 27: 1401-1409, 2005.

14. Cohen JI: HMG CoA reductase inhibitors (statins) to treat Epstein-Barr virus-driven lymphoma. Br J Cancer 92: 1593-1598, 2005.

15. Golab J, Nowis D, Skrzycki M, Czeczot H, Baranczyk-Kuzma A, Wilczynski GM, Makowski M, Mroz P, Kozar K, Kaminski R, Jalili A, Kopec M, Grzela T and Jakobisiak M: Antitumor effects of photodynamic therapy are potentiated by 2-methoxyestradiol. A superoxide dismutase inhibitor. J Biol Chem 278: 407-414, 2003.

16. Golab J, Stoklosa T, Czajka A, Dabrowska A, Jakobisiak M, Zagozdzon R, Wojcik C, Marczak M and Wilk S: Synergistic antitumor effects of a selective proteasome inhibitor and TNF in mice. Anticancer Res 20: 1717-1721, 2000.

17. Feleszko W, Balkowiec EZ, Sieberth E, Marczak M, Dabrowska A, Giermasz A, Czajka A and Jakobisiak M: Lovastatin and tumor necrosis factor-alpha exhibit potentiated antitumor effects against Ha-ras-transformed murine tumor via inhibition of tumor-induced angiogenesis. Int J Cancer 81: 560-567, 1999. 
18. Nowis D, Legat M, Grzela T, Niderla J, Wilczek E, Wilczynski GM, Glodkowska E, Mrowka P, Issat T, Dulak J, Jozkowicz A, Was H, Adamek M, Wrzosek A, Nazarewski S, Makowski M, Stoklosa T, Jakobisiak M and Golab J: Heme oxygenase-1 protects tumor cells against photodynamic therapymediated cytotoxicity. Oncogene 25: 3365-3374, 2006.

19. Jakobisiak M, Bruno S, Skierski JS and Darzynkiewicz Z: Cell cycle-specific effects of lovastatin. Proc Natl Acad Sci USA 88: 3628-3632, 1991.

20. Keyomarsi K, Sandoval L, Band V and Pardee AB: Synchronization of tumor and normal cells from G1 to multiple cell cycles by lovastatin. Cancer Res 51: 3602-3609, 1991.

21. Giermasz A, Makowski M, Kozlowska E, Nowis D, Maj M, Jalili A, Feleszko W, Wojcik C, Dabrowska A, Jakobisiak M and Golab J: Potentiating antitumor effects of a combination therapy with lovastatin and butyrate in the Lewis lung carcinoma model in mice. Int J Cancer 97: 746-750, 2002.

22. Alonso DF, Farina HG, Skilton G, Gabri MR, De Lorenzo MS and Gomez DE: Reduction of mouse mammary tumor formation and metastasis by lovastatin, an inhibitor of the mevalonate pathway of cholesterol synthesis. Breast Cancer Res Treat 50: 83-93, 1998.

23. Matar P, Rozados VR, Binda MM, Roggero EA, Bonfil RD and Scharovsky OG: Inhibitory effect of lovastatin on spontaneous metastases derived from a rat lymphoma. Clin Exp Metastasis 17: 19-25, 1999.
24. Jani JP, Specht S, Stemmler N, Blanock K, Singh SV, Gupta V and Katoh A: Metastasis of B16F10 mouse melanoma inhibited by lovastatin, an inhibitor of cholesterol biosynthesis. Invasion Metastasis 13: 314-324, 1993.

25. Soma MR, Baetta R, De Renzis MR, Mazzini G, Davegna C, Magrassi L, Butti G, Pezzotta S, Paoletti R and Fumagalli R: In vivo enhanced antitumor activity of carmustine [N, N'-bis(2chloroethyl)-N-nitrosourea] by simvastatin. Cancer Res 55: 597-602, 1995.

26. Graaf MR, Beiderbeck AB, Egberts AC, Richel DJ and Guchelaar HJ: The risk of cancer in users of statins. J Clin Oncol 22: 2388-2394, 2004.

27. Poynter JN, Gruber SB, Higgins PD, Almog R, Bonner JD, Rennert HS, Low M, Greenson JK and Rennert G: Statins and the risk of colorectal cancer. N Engl J Med 352: 2184-2192, 2005.

28. Iizuka N, Hazama S, Yoshimura K, Yoshino S, Tangoku A, Miyamoto K, Okita K and Oka M: Anticachectic effects of the natural herb Coptidis rhizoma and berberine on mice bearing colon 26/clone 20 adenocarcinoma. Int J Cancer 99: 286-291, 2002 . 